\title{
POPULATION'S VULNERABILITY TO NATURAL DISASTERS IN RUNNYMEDE VILLAGE AT TZANEEN LOCAL MUNICIPALITY, SOUTH AFRICA
}

\author{
F.K. Matlakala ${ }^{1^{*}}$, L. Nyahunda ${ }^{2}$, J.C. Makhubele ${ }^{3}$ \\ ${ }^{1 *}$ Ph.D. Candidate, Department of Social Work, University of Limpopo, South Africa; ${ }^{2}$ Research Associate, Research \\ Office, University of Limpopo, South Africa; ${ }^{3}$ Research Professor, Department of Social Work, University of Limpopo, \\ South Africa. \\ Email: ${ }^{1 *}$ fransmatlakala@gmail.com, ${ }^{2}$ nyahundalouis@gmail.com, ${ }^{3}$ jabulani.makhubele@ul.ac.za \\ Article History: Received on $30^{\text {th }}$ July 2021, Revised on $10^{\text {th }}$ August 2021, Published on $12^{\text {th }}$ August 2021
}

\begin{abstract}
Purpose of the study: This paper was aimed at determining the population's vulnerability to natural disasters in Runnymede Village at Tzaneen Local Municipality, South Africa.

Methodology: The researchers used the qualitative research approach and the exploratory research design. A total number of 16 participants took part in the study. The participants consisted of small-scale farmers, social workers, and disaster management members. Data was collected through individual semi-structured and focus group interviews and was analysed thematically.
\end{abstract}

Main Findings: The study found that impoverished people in the rural areas, people living with disabilities, children, and women are mainly vulnerable to natural disasters. The study thus concludes that people in rural areas are more prone to the impact of natural disasters due to geopolitical, structural, and cultural systems.

Applications of this study: People's relatives, friends, and others close to them can disappear alongside their livelihoods, homes, hospitals, roads, transport, telecommunications networks, and schools. These effects trigger various emotions such as fear, anger, and grief to community members. To this end, community members will receive holistic intervention from relevant social workers, who will be providing psychosocial support.

Novelty/Originality of this study: This study contributes positively to the field of social service, and provides guidelines to social workers to address natural disasters. Due to their educational background, social workers should fight the injustices that people in rural areas are predisposed to. They could challenge these injustices (inequalities) as these infringe on individuals' rights to dignity and other associated rights.

Keywords: Climate Change, Disability, Natural Disasters, Population, Rural Areas, Vulnerable.

\section{INTRODUCTION}

With the growing threat of climate change and climate-related disasters, communities must be empowered to reduce their vulnerability. In support, several authors have underscored that the vulnerability of rural communities and developing countries to climate-related disasters is a result of poor adaptation strategies (Enete \& Achike, 2008; Nyahunda \& Tirivangasi 2019). Furthermore, Ndaki (2014) wrote that developing countries' inability to cope with the effects of climate change is due to a lack of financing for climate change adaptation. Easton and Sommers (2003) earlier reported that the government is entrusted with funds to develop along with societies' ideas and programmes that are used to develop policies that address the needs of people. Nyahunda and Tirivangasi (2019) state that members of the ruling political structure are the ones who receive preference compared to vulnerable community members. As such, social workers should advocate for the equal distribution of resources needed to respond to the effects of climate change, especially for the vulnerable groups in rural areas.

Given poor adaptation strategies and poor communication status, there is a high poverty rate and poor agricultural production in rural communities. This was supported by Conway (2009), who stated that the agriculture and mining sector's rural communities are faced with high unemployment and low productivity. This leads to poverty arising from instability in the economy as a result of unpredictable weather conditions. In the same vein, Bisht (2013) further articulated that in rural communities, due to water shortage, there is crop failure and the death of livestock. It is for this reason that Turpie and Visser (2013) and Nyahunda and Tirivangasi (2019) positioned rural communities as the most vulnerable population to the effects of climate change as they mainly depend on agriculture for survival.

Chisango and Maposa (2016) state that the majority of studies conducted on the effects of climate change have focused on urban areas, and disregarded challenges faced by rural areas in mitigating the effects of climate change. However, of late, Nyahunda and Tirivangasi (2019) and Nyahunda, Makhubele, Mabvurira, and Matlakala (2020) have conducted studies on challenges faced by rural communities, stating that these communities experience a decline in agricultural production and economic productivity, and an increase in poverty and food insecurity as a result of climate change. As such, the first point of departure to deal with the effects of climate change is for communities to address the issue of poverty (Brooks \& Loevinsohn, 2011; Nyahunda \& Tirivangasi 2019). In light of the above, this paper was aimed at 
determining the population's vulnerability to natural disasters in rural communities at Tzaneen Local Municipality, South Africa.

\section{METHODOLOGY}

Research Design: This study adopted the qualitative research approach due to its ability to ensure that participants provide in-depth information on the phenomenon. According to Kumar (2011), the qualitative research approach is ideal when one attempts to gain rich information from participants as it allows flexibility during the data collection process. The researchers opted for exploratory research design as they wanted to gain contextual in-depth information about the population that is vulnerable to natural disasters. According to de Vos, Strydom, Fouché, and Delport (2011), exploratory design is used when little is known about the phenomenon. In this case, there is a dearth of information on the population that is vulnerable to natural disasters, especially in deprived communities.

Sample: Participants were sampled using the purposive sampling technique, which is used when the researcher purposively selects participants that will help him or her to meet the research aim (de Vos et al., 2011). As such, in this study, researchers purposively selected five (5) social workers as key informants due to their scope of practice and their role during natural disasters (providing psychosocial support and social relief of distress) (Zastrow, 2017). Moreover, the

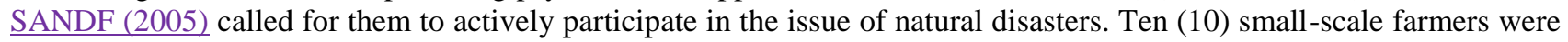
purposively selected to form part of this study as community members due to their accessibility, availability, and vulnerability to disasters when executing their activities. Lastly, one disaster management member was included in the study as a key informant to share information on his line of duty.

Data collection and interpretation: Data was collected through individual semi-structured interviews and focus group discussions. The interviews were used with social workers and disaster management members for four days. Focus Group Discussion (FGD) was used to collect data from small-scale farmers. Thematic Content Analysis was used to analyse data. According to O'Leary (2017), Thematic Content Analysis is a method of identifying, analysing, and reporting patterns (themes) within the data, which minimally organises and describes the data set in (rich) detail. The researchers chose this data analysis technique due to its ability and potential to further interpret and highlight emerging themes and aspects about social workers' intervention during natural disasters.

Ethical consideration: The researchers received ethical clearance from Turfloop Research Ethics (TREC). They used semi-structured interviews to collect data from social workers. During data collection, the researchers followed the health precaution measures put in place by the National Command Council of Corona Virus regulations. They ensured that all participants wore a face mask, sanitised, and maintained a 2-metre distance during interviews. Moreover, those with underlying health conditions were requested to declare before the interview and were allowed to withdraw from the study without penalty.

\section{FINDINGS AND DISCUSSION}

Under-development in terms of technological backlashes, economic constraints, low educational levels, poor infrastructural development, and dependence on livelihoods makes individuals susceptible to natural. In light of this, it emerged that vulnerability to natural disasters can be compartmentalised according to demographic variables. That being the case, there was an acknowledgment that children, women, and people with disabilities were susceptible to natural disasters. On that note, participants had mixed views in explaining vulnerability to natural disasters amongst these populations.

\section{The impoverished people in rural areas}

The gap between the rich and the poor has widened in Africa. As a developing country, South Africa is not an exception. In particular, the ones who bear the brunt are those who reside in rural areas. The unbearable conditions are compounded by inequalities and patriarchal systems entrenched through cultural norms, values, and practices. In addition to this, the occurring and recurring natural disasters exacerbate the calamity of people in rural areas. Such challenges experienced by rural people are geopolitical and structural. In fact, Nyahunda (2020) posits that in South Africa, the apartheid regime relocated people to the poor, dry, and barren land that is more prone to natural disasters. However, the researchers do not dispute the sentiments of the latter author but believe that in addition to geopolitical and structural factors, cultural (patriarchal) factors played a major role in contributing to people's location in rural areas.

As such, it can be deduced that due to geopolitical, structural (apartheid system), and cultural systems, compounded by unpredictable natural disasters, people in rural areas find themselves under-resourced and under-developed. In support, the small-scale farmer stated:

\footnotetext{
"We were forcefully removed from fertile land and be dumped here in this dry, barren land. We have to survive under these conditions and come up with ways or strategies to survive in such a dry land." (Participant 5, small-scale farmer, FGD).
}

In corroboration, another small-scale farmer echoed that: 
"As we are in a dry land, our parents taught us that for us to know that there would be enough rain to plough the land, we used to observe ants as they predicted rainfall. We would know when to start tilling the land after such observations." (Participant 7, small-scale farmer, FGD)

Concerning cultural factors in a particular patriarchal system, another small scale farmer stated that:

"It has been a norm and practice that women have no ownership when it comes to land, theirs is to plough and those who were on their menstrual periods were not allowed to enter the fields as the practice or custom is that they will have the spell to the harvest." (Participant 8, small-scale farmer, FGD)

Of all the views on the issue of rural people who are affected by natural disasters, the most striking one was by the Social Worker, who said that:

"Rural people who experience natural disasters end up being impoverished, however, most are women who, culturally, are not allowed to own the land. One should also be careful as other groups such as women and children as a result of natural disasters, bear the price of poverty and unemployment is very rife. In addition, psychosocial ills are the offshoots of these conditions." (Participant 13, social worker)

In support, the disaster management officer concurred that people in rural areas were impoverished. He stated that:

"People in rural areas are mainly affected by natural disasters [showed a picture of areas that they assisted]. After disasters, we write a post-disaster assessment report whereby we request the Human Settlement Department to assist the impoverished people with temporary shelter" (Participant 16, Disaster Management Officer)

The above findings show that due to geopolitical, structural (apartheid), and cultural systems, rural participants found themselves in impoverished areas that predisposed them to natural disasters. In line with the key tenet of the Vulnerability Theory (liability), the susceptibility of participants was the result of occupying areas that were unsafe for human habitation and not fertile for agricultural purposes. In the terrain of social work practice, social workers are wellpositioned to fight the injustices that women are predisposed to. They could challenge those injustices (inequalities and patriarchal systems about land ownership) as these infringe on women's rights to dignity and other associated rights.

\section{People living with disabilities}

Dry, infertile land where people reside predisposes community members in general and small-scale farmers in particular to natural disasters. Other community members experience the second-degree impact of natural disasters. Amongst them were people living with disabilities. The findings below indicate that persons living with disabilities are exposed to an unfriendly environment. For instance, a disabled man was found staying in a hut that did not have a roof. He was vulnerable, left alone to natural disasters such as floods and hailstorms. One of the small-scale farmers narrated the following:

"Someone is living with a disability (paraplegic) in this village. The condition of the house he lives in is in appalling condition, one could see through the roof of the house. Seemingly his significant others are not taking care of him. He was supposed to benefit from the government emergency housing programme which never materialised. So that person is still in need." (Participant 2, small-scale farmer, FGD).

In line with the above assertion, one of the key informants (Disaster Management Officer) averred that people living with disabilities are vulnerable to natural disasters. The following assertions were shared:

"Due to their immobility, people with disabilities, especial those who depend on people to move around are more vulnerable to natural disasters. When they [people living with a disability] experience a sudden disaster, due to their disability, they fail to move to a place of safety quickly. When coming to evacuate them, we also face a challenge as we have to carry those on the wheelchair to a safer place which is not easy." (Participant 16, Disaster Management Officer)

People living with disabilities are, in most instances, disadvantaged by the environment in which they find themselves. More often than not, they are rejected by their able relations. In addition, there is no visitation or care from family members and friends as espoused by the philosophy of Ubuntu. In a study conducted by Coates (2014), it was revealed that people living with disabilities, whether acquired from birth or accident, experience hardships and find it difficult to carry out day-to-day activities. For the reason that they are unable to participate in community activities, they end up being isolated and unable to flourish in life. This corroborates previous findings by Coate (ibid), as mentioned earlier, about an individual who was in a wheelchair and resided alone in a hut "rondavel house". The individual was told he could not receive a government-funded house (commonly known as RDP house) as he is receiving a disability grant. The reason being that he could not dip twice into government coffers.

Putting it in the context of the vulnerability theory, one of the key tenets (capabilities) stresses that protective factors make an individual resilient to natural disasters. In this instance, it is expected that the extended family will serve as a buffer against odds. Moreover, the person in a wheelchair needs social support system for livelihood. Its absence makes 
him doubly susceptible to natural disasters. This was substantiated by Zakour (2015), who stated that people with disabilities and those with mental disorders are more susceptible to natural disasters than those with none. In addition, due to the disability of the individual, he may have challenges in comprehending, for instance, early disaster warning signs, and his property may be destroyed.

The individual might not be aware that social workers, given their educational background, are well placed to advocate for him to access services. Zakour and Gillespie (2013) propound that social workers should use their skills and roles to provide services and to maximise the safety of individuals in their community. As it is, the individual is not safe and has not received services. This infringes on his right to human dignity. It is for this reason that researchers believe that the social worker should assume the role of an advocate and assist the person to get a government-funded house.

\section{Children}

Children are the future of any nation - herein defined according to the Children's Act 38 of 2005 as persons under the age of 18 - and represent a portion of those significantly enduring the impact of natural disasters much like disabled people. Be that as it may, researchers continue to overlook the experiences of children and their needs during natural disasters. The above assertion about the exclusion of children in research is well captured by La Greca and Prinstein (2002), who stated that researchers assume that children cannot be affected by disasters, and that their reaction is shortlived. Furthermore, Anderson (2005) highlighted that research on disasters overlooks children due to socio-cultural and structural processes in society. In other words, those who research children find it difficult due to the tedious process they have to follow. However, the truth of the matter is that no one is immune from natural disasters irrespective of age, gender, creed, sex, or sexual orientation. Peek (2008) reported that there would be an increase in the number of children affected by natural disasters in the twenty-first century. In this study, a social worker stated that:

"During the occurrence of natural disasters, we realised that children are affected and it is very painful as some end up losing their school books, clothes and their parents sometimes have to be relocated to the safer place far from their school." (Participant 12, Social Worker)

In addition, another social worker reported the second-degree impact of natural disasters on children, stating that:

"Children become scared during disasters and aftermath of the disaster, manifestations of posttraumatic stress disorder, anxiety, and delusion are evident." (Participant 14, Social Worker)

On the same wavelength, another social worker reported that:

"Children as a result of the second-degree impact of natural disasters, due to its nature of the emergency, without proper shelters, some are victims of domestic violence, rape and sexual assaults." (Participant 15, Social Worker)

Another key informant, the Disaster Management Officer, avowed that:

"When there is a sudden flood, children cannot quickly think of ways to save themselves. This comes down to their inability to respond to natural disasters due to lack of capacity to make rational decisions. " (Participant 16, Disaster Management Officer)

The above findings point out that children experience the impact of natural disasters just like other people. In the process, they lose their valuables. As a result of natural disasters, children are traumatised and experience posttraumatic stress disorder. The study affirmed findings by Fernandes, Boehs, Denham, Nitschke, and Martini (2017), who averred that natural disasters cause trauma to individuals, families, and communities. In the case of loss of life as a result of natural disasters, children may be faced with the new reality of living without parents. This is the secondary impact of natural disasters. During such events, disaster management teams are called to provide services ranging from evacuation to relocation to safe places. This is done in collaboration with other key stakeholders like health providers, who provide emergency medical health services and social welfare for food distribution. Sometimes, external family members will normally come to provide protection, care, and support to the affected children.

\section{Women}

Women are custodians of families. They rear children, till the land, and ensure that basic needs are met. Traditionally, women's roles have been in the kitchen, but with industrialisation, they are in leadership positions. They also head families. Despite the invaluable roles they play in society, particularly in rural areas where patriarchy still rears its head, natural disasters add a burden to them. For women who are in the agricultural sector doing subsistence farming to provide for their families, the occurrence of natural disasters hinders their progress and production. Secondary to this, as a result of natural disasters, which in the main are floods and droughts, women are left with no option but to remain at home. Consequently, overtly or covertly, unintended consequences such as domestic violence, intimate partner violence, and other social ills befall them. In shedding light on the vulnerabilities of women in the agricultural sector, on the facevalue structural level, one of the small-scale farmers stated that: 
"During floods, our crops are washed away or lose production and as a result, we are unable to harvest the expected yields." (Participant 3, small-scale farmer, FGD)

Another participant (small scale farmer) said that:

"Our area is prone to droughts and it is very difficult to sustain families as in addition to drought, unemployment and poverty is very rife." (Participant 7, small-scale farmer, FGD)

From the viewpoints of social workers regarding second-degree vulnerabilities of women due to natural disasters, this was echoed:

"Even though they provide food and take care of the children, some women are exposed to all sorts of social ills such as gender-based violence, rape and sometimes get killed by their spouses." (Participant 15, Social Worker)

In support, the Disaster Management Officer offered the following viewpoint regarding second-degree vulnerabilities of women due to natural disasters:

"During the evacuation process, we place community members in the same venue. In that venue [community hall] there is no enough space which might expose women to experience all forms of abuse as they are in one space with men." (Participant 16, Disaster Management Officer)

The findings of this study substantiate the already existing literature which posits that globally, women cannot perform their roles. They suffer from all sorts of social ills as a result of natural disasters. A plethora of cyclones that have been ravaging the Southern African region since 2000 bear testimony to the fact that women were disproportionally affected by natural disasters than men (Chatiza 2019). From this, the post evaluation of the impacts of Cyclone Idai which ravaged Mozambique, Zimbabwe, and Malawi in March 2019 left footprints of devastating impacts on women than men. Sadly, women were subjected to multifarious challenges in temporary rescue camps created by humanitarian organisations. Cases of sexual harassment and domestic violence galloped. Women were more traumatised from the harrowing experiences than men. Their sexual and reproductive health plummeted, and the poverty level increased. Furthermore, they constituted the highest number of the injured and the displaced (Chanza \& Gundu-Jakarasi 2020; Nyahunda, Matlakala, \& Makhubele, 2020a). In the aftermath of cyclone Idai, the health of women, their psychosocial wellbeing, sanitation, sexual reproductive health, food security, bargaining power, and security were compromised in rescue shelters created by humanitarian organisations (Nyahunda, Matlakala \& Makhubele, 2020b).

Opondo, Abdi, and Nangiro (2016) reported that during the drought in Uganda, there was a surge in child marriage, domestic violence, and rape. What is responsible for women's vulnerability to gender-based violence during natural disasters is that it is in these times that they lose their source of income. This has been confirmed by CARE International (2014). During and after disasters, men take advantage of women's social status, thereby subjecting them to all forms of despicable treatment, knowing that they will not be reported as they are breadwinners during natural disasters. Some even solicit women/girls for sexual acquiescence in exchange for food and other assets (Baten \& Khan 2010). What should be underscored is that the vulnerability of women during and post disasters is attributed to the conditions that predispose them to disaster in the society, such as exclusion from disaster preparedness planning processes, confinement to household responsibilities owing to ascribed gender roles, low social status and lack of bargaining power (Bradshaw, 2013). The Vulnerability Theory underpins that women have distinct vulnerabilities. This informs their differential abilities in experiencing, and recovery from, disasters (Bankoff, Frerks, \& Hilhorst, 2013).

\section{CONCLUSION AND RECOMMENDATIONS}

In this study, it was established that under-development in terms of technological backlashes, economic constraints, low educational levels, poor infrastructural development, and dependence on livelihoods susceptible to natural disasters formed an interplay of factors behind the vulnerability of Runnymede village to natural disasters. The researchers concluded that people in rural areas are more prone to the impact of natural disasters due to geopolitical, structural, and cultural systems. On that score, it is recommended that due to their educational background, social workers should fight the injustices that people in rural areas are predisposed to. They could challenge these injustices (inequalities) because they infringe on individuals' rights to dignity and other associated rights.

Children experience the impact of natural disasters just like other people. They lose their valuables in the process and experience posttraumatic stress disorder. Moreover, in the case of loss of life as a result of natural disasters, children face the new reality of living without parents. During such events, disaster management teams are called to provide services ranging from evacuation to relocation to safe places. This is done in collaboration with other key stakeholders like health, who provide emergency medical health services and social welfare for food distribution. Sometimes extended family members would come to provide protection, care, and support to the affected children. It is recommended that social workers should be actively involved in the evacuation process to ensure that the wellbeing of children is protected against social ills, and to take them to places of safety. Again, women are more susceptible to natural disasters as a result of the patriarchal system which sees them belonging in the kitchen. They are unable to participate in farming to care for their children. Moreover, during natural disasters, they are forced to stay at home. This predisposed them to suffer many 
forms of abuse from their partners. Therefore, the study recommends that women should fight for equal rights to practise farming, and be funded by policymakers to grow their agricultural products.

\section{LIMITATION AND STUDY FORWARD}

The research findings are limited to Runnymede village, and cannot be generalised as practice in the whole of Tzaneen Municipality of South Africa. The researchers did not generalise the findings due to their small size and the nature of the research approach.

\section{ACKNOWLEDGEMENT}

The authors will like to acknowledge National Research Foundation for the funding (Grand ID: 121749).

\section{AUTHORS CONTRIBUTION}

F.K. Matlakala: This study was harvesting from the Ph.D. thesis of the lead author.

L. Nyahunda: This co-author was a co-supervisor of the lead author and assisted with reviewing the manuscript.

J.C. Makhubele: This co-author was the main supervisor and proofread the manuscript.

\section{REFERENCES}

1. Anderson, W. A. (2005). Bringing children into focus on the social science disaster research agenda. International Journal of Mass Emergencies and Disasters, 23(3), 159-175.

2. Bankoff, G., Frerks, G., \& Hilhorst, D. (Eds.). (2013). Mapping Vulnerability: Disasters, Development and People. Routledge. https://doi.org/10.4324/9781849771924

3. Baten, M. A., \& Khan, N. A. (2010). Gender issue in climate change discourse: theory versus reality. Unnayan Onneshan, Dhaka.

4. Bisht, I. S. (2013). Biodiversity conservation, sustainable agriculture and climate change: A complex interrelationship. In knowledge systems of societies for adaptation and mitigation of impacts of climate change, S. Nautiyal et al. (Eds.), Environmental Science and Engineering. Springer. https://doi.org/10.1007/978-3-64236143-2_8

5. Chisango, F.F.T., \& Maposa, A. (2016). Impacts of Erotic Weather Patterns as a Result of Climate Change and Variability on Food Crop Productivity and Food Security in Zimbabwe's Arid Regions of Matabeleland; A Case of Siabuwa Communal Area in Binga District. Greener Journal of Agricultural Sciences, 6(3), 127-133. http://doi.org/10.15580/GJAS.2016.3.030316054

6. Bradshaw, S. (2013). Gender, development and disasters. Edward Elgar Publishing. https://doi.org/10.433 7/9781782548232

7. Brooks, S. \& Loevinsohn, M. (2011). Shaping agricultural innovation systems responsive to food insecurity and climate change. Natural Resources Forum, 35(3), 185-200. https://doi.org/10.1111/j.1477-8947.2011.01396.x

8. CARE International. (2014). 'The girl has no rights': Gender-based violence in South Sudan. CARE Emergencies.

9. Chanza, N., \& Gundu-Jakarasi, V. (2020). Deciphering the climate change conundrum in Zimbabwe: An Exposition. In Global Warming and Climate Change. IntechOpen. https://doi.org/10.5772/intechopen.84443

10. Chatiza, K. (2019). Cyclone Idai in Zimbabwe: An analysis of policy implications for post-disaster institutional development to strengthen disaster risk management. Oxfam. https://doi.org/10.21201/2019.5273

11. Coates, P. (2014). Borderland, no-man's land, nature's wonderland: troubled humanity and untroubled earth. Environment and History, 20(4), 499-516. https://doi.org/10.3197/096734014X14091313617244

12. Conway, G. (2009). The science of climate change in Africa: Impacts and adaptation, Grantham Institute for Climate Change Discussion Paper, Retrieved 20 September 2016, from http://www.ask-force.org/web/GlobalWarming/Convay-Science- Climate-Change-Africa-2008.pdf.

13. De Vos, A.S., Strydom, H., Fouché, C.B \& Delport, C.S.L. (2011). Research at Grass Roots: For the social sciences and human service professions, $\left(4^{\text {th }}\right.$ ed.). van Schaik Publishers.

14. Easton, P.D. \& Sommers, G.A. (2003). Scale and the scale effect in Market based accounting research. Journal of Business Finance and Accounting, 30(1-2), 25-56. https://doi.org/10.1111/1468-5957.00482

15. Enete, A. A. \& Achike, A. I. (2008). Urban agriculture and urban food insecurity/poverty in Nigeria: The case of Ohafia Southeast Nigeria. Outlook on Agriculture, 37(2), 131-134. https://doi.org/10.5367 1000000008784648915.

16. Fernandes, G. C. M., Boehs, A. E., Denham, S. A., Nitschke, R. G., \& Martini, J. G. (2017). Rural families' interpretations of experiencing unexpected transition in the wake of a natural disaster. Cadernos de saude publica, 33, 1-11. https://doi.org/10.1590/0102-311X00161515

17. Kumar, R. (2011). Research methodology: A step-by-step guide for beginners. New Sage Publications Limited.

18. La Greca, A. M., \& Prinstein, M. J. (2002). Hurricanes and earthquakes. In A. M. La Greca, W. K. Silverman, E. M. Vernberg, \& M. C. Roberts (Eds.), Helping children cope with disasters and terrorism (pp. 107-138). Washington, DC: American Psychological Association. https://doi.org/10.1037/10454-005 
19. Ndaki, P.M. (2014). Climate change adaptation for smallholder farmers in rural communities: The case of Mkomazi sub-catchment, Tanzania (PhD dissertation). University of Oldenburg.

20. Nyahunda L., \& Matlakala, F.K. \& Makhubele, J.C. (2020a). Factors impeding the participation of rural women in climate change issues in Vhembe District, Limpopo Province, South Africa: A requirement for social work intervention. The Southern African Journal of Social Work and Social Development, 14(2), https://doi.org 10.25159/2415-5829/7771.

21. Nyahunda L., Matlakala, F.K. \& Makhubele, J.C. (2020b). Environmental social work: Accounting for women's tragedies in the face of climate change induced disasters in Chimanimani District, Zimbabwe. African Journal of Gender, Society and Development, 9 (4):197-127. https://doi.org/10.31920/2634-3622/2020/v9n4a9

22. Nyahunda, L., \& Tirivangasi, H.M. (2019). Challenges faced by rural people in mitigating the effects of climate change in the Mazungunye communal lands, Zimbabwe. Jàmbá: Journal of Disaster Risk Studies. 11(1), 1-9 https://doi.org/10.4102/jamba.v11i1.596

23. Nyahunda, L. (2020). Participation of Rural Women in Mitigating the Effects Of Climate Change in Vhembe District, Limpopo Province, South Africa Unpublished Thesis in Social Work. University of Limpopo.

24. Nyahunda, L., Makhubele, J. C., Mabvurira, V., \& Matlakala, F. K. (2020). Vulnerabilities and Inequalities Experienced by Women in the Climate Change Discourse in South Africa's Rural Communities: Implications for Social Work. The British Journal of Social Work. https://doi.org/10.1093/bjsw/bcaa118.

25. O'Leary, Z. (2017). The Essential Guide to Doing your Research Project. Sage Publications.

26. Opondo, M., Abdi, U., \& Nangiro, P. (2016). Assessing gender in resilience programming: Uganda. BRACED Resilience Intel, 2(2), 1-16.

27. Peek, L. (2008). Children and disasters: Understanding vulnerability, developing capacities, and promoting resilience-An introduction. Children Youth and Environments, 18(1), 1-29.

28. South African National Disaster Framework [SANDF]. (2005). Introduction: A policy framework for disaster risk management in South Africa. Government Printer.

29. Turpie, J. \& Visser, M., 2013. The impact of climate change on South Africa's rural areas. Financial and Fiscal Commission, 14, 100-160.

30. Zakour, M. J. (2015). Effects of support on evacuation preparedness of persons with disabilities. Journal of social work in disability \& rehabilitation, 14(1), 1-22. https://doi.org/10.1080/1536710X.2015.989561

31. Zakour, M., \& Gillespie, D. (2013). Community disaster vulnerability: theory, research, and practice. Springer. https://doi.org/10.1007/978-1-4614-5737-4

32. Zastrow, C. (2017). Introduction to social work and social welfare: Empowering people. (12 ${ }^{\text {th }}$ ed.). Cengage Learning. 